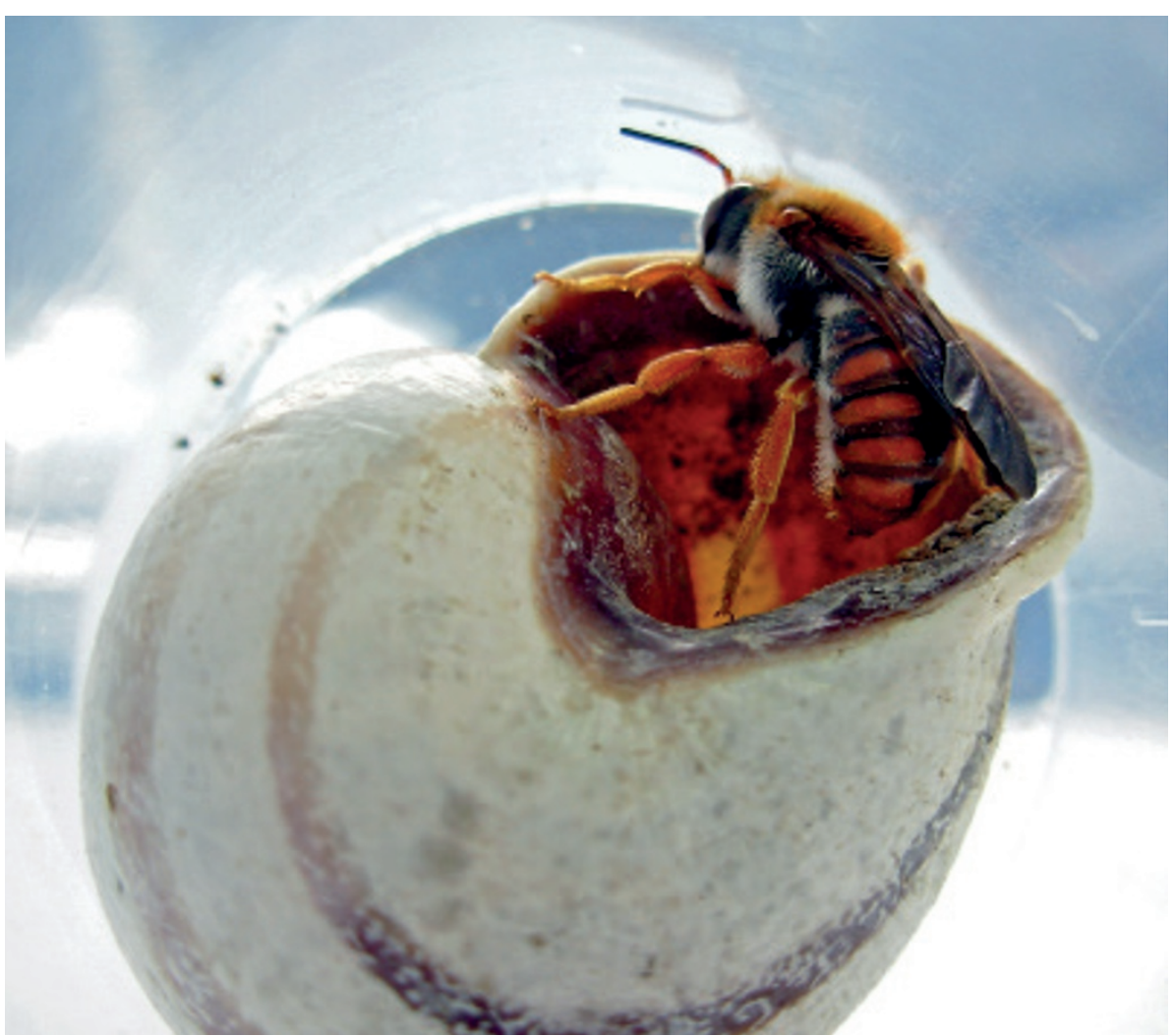

A male mason bee, Rhodanthidium sticticum, makes its nest in the empty shell of an Otala snail.

\title{
WILD BEES
}

\section{Lone rangers}

\section{Solitary bees receive scant attention, but research shows that they are vital pollinators of crops and wild habitats.}

\section{BY LUCAS LAURSEN}

$\mathrm{I}$ $\mathrm{n}$ a green field outside Madrid, at the foot of the snow-covered Guadarrama mountain range, lies a sun-faded snail shell. Its opening sealed with a cap of dried mud, the shell contains the larva of a wild, solitary bee, together with its first meal of bee bread - a mixture of pollen and nectar. Entomology graduate student Daniel Romero picks up the shell and, concluding that it contains the nest of a mason bee, stores it in a clear plastic tube, labels the red cap with a marker, and closes it.

Back at the Complutense University of Madrid, Romero sets ten tubes of the nesting bees he collected on his professor's desk. They are just a fraction of the hundreds of samples that he and his colleagues will gather during a four-year Spanish government-funded study of how artificial chemicals are affecting the biodiversity of wild pollinators and their immune and reproductive systems. In the warmth of the office, some of the young adults twitch and scratch at their now-crumbly mud indiscriminate pollinators, solitary bees have co-evolved relationships with specific flowering plants: some feed on only one species, and have probosces and leg- and body-hairs that have adapted to the shape of their favourite flowers. As a result, solitary bees can be more efficient pollinators of these favoured plants than honeybees. The diversity of solitary bees also means that they have a different range of tolerances for environmental conditions, such as temperature, wind speed and the number of daylight hours - so a farmer or conservationist managing the needs of these bees requires a larger range of techniques.

The life cycles of solitary species share some similarities: the insects collect and eat pollen, some of which they store for their offspring to eat when they hatch. But most solitary bees do not produce honey, which means that - until the late twentieth century - humans intent on agriculture more or less neglected them.

Hence Romero's fieldwork. He and his supervisor, entomologist Concepción Ornosa, spurred by worries about the decline in honeybee and bumblebee populations, started a project to examine how susceptible solitary bees are to the same hazards. Some of the work is fairly basic. "In Spain, we're still learning what bees there are," Ornosa says. The Iberian peninsula hosts nearly 1,000 of Europe's estimated 2,000 bee species, of which only a handful are well-described in taxonomic literature. The European Red List of Bees (A. Nieto et al. European Red List of Bees (European Commission, 2014); available at go.nature.com/c4g8lm), showed that both the diversity of bee species and the number with incomplete descriptions is higher in Spain than anywhere else in Europe. After identifying species, Ornosa's team must map their distribution before they can examine how healthy the populations are and what environmental risks might threaten them. Then the real work begins: trying to quantify the impact of different kinds of environmental pollutants on wild-bee health and biodiversity.

\section{GOVERNMENT INTEREST}

Efforts by researchers to learn more about wild bees are starting to inform policy. Three years ago, the European Food Safety Authority (EFSA) commissioned a scientific working group to help draft risk-assessment guidance that, for the first time, considers honeybees, bumblebees and solitary bees separately. The updated guidance, published in 2013 but still under review, could arm regulators with the information they need to include wild bees (both social and solitary) in their landmanagement plans and tests for new pesticides. Right now, the rules treat all bees the same, yet practices designed to protect honeybees may not prevent wild bees from absorbing toxic chemicals, given their very different life cycles. "You can't really extrapolate from A. mellifera," says entomologist Fabio 
Sgolastra of the University of Bologna in Italy, who co-authored the scientific opinion that underpins the EFSA guidance document.

Sgolastra expects objections from farmers and pesticide companies because the new risk-assessment guidance requires more tests to ensure the lowest risk possible to the health of all bee species. "It's quite conservative," he says. Still, Sgolastra argues that although these tests might be expensive, in the long run they will pay off. A UK study found that honeybee pollination capacity is falling: the insects supply only one-third of demand, the remainder being picked up by wild pollinators including bees. And in the United States, wild bees were the most

frequent visitors to three out of four crops studied. Growers and governments are now struggling to strike a balance between protecting wild pollinators and maintaining existing production levels.

The United States, too, is looking to protect its pollinators. In June 2014, President Barack Obama initiated a pan-agency review, which sent researchers across the country scrambling for evidence of the health or otherwise of its pollinators, says US Department of Agriculture (USDA) entomologist Theresa Pitts-Singer. The draft report, expected to be published this spring, will probably call for more basic research on wild-bee populations and how pesticides affect them. Whether

"In Spain, we're still learning what bees there are." these recommendations will be implemented will depend on how much money Congress allocates in response - the task-force report has no direct regulatory power. Pitts-Singer - who works in Logan, Utah, at the only USDA laboratory dedicated to studying the use of solitary bees in agriculture - is hopeful that this could bring the needed funding for solitary-bee research in the United States. "If we're going to get it," she says, "it's going to happen now."

\section{AGRICULTURAL APPLICATIONS}

Agronomic research on wild bees has a short history. After the Second World War, Japanese farmers began managing wild-bee populations by building portable nests, replacing honeybee populations devastated by overuse of pesticides such as DDT. US researchers began promoting the practice to US farmers in the 1970s, using both domestic and Japanese species of wild bees.

The USDA provides some research support for farmers for the alfalfa leafcutter bee, Megachile rotundata, and for the blue orchard bee, Osmia lignaria, both of which are solitary. But these two wild-bee species are the exceptions. Entomologist Jordi Bosch of the Autonomous University of Barcelona in Spain

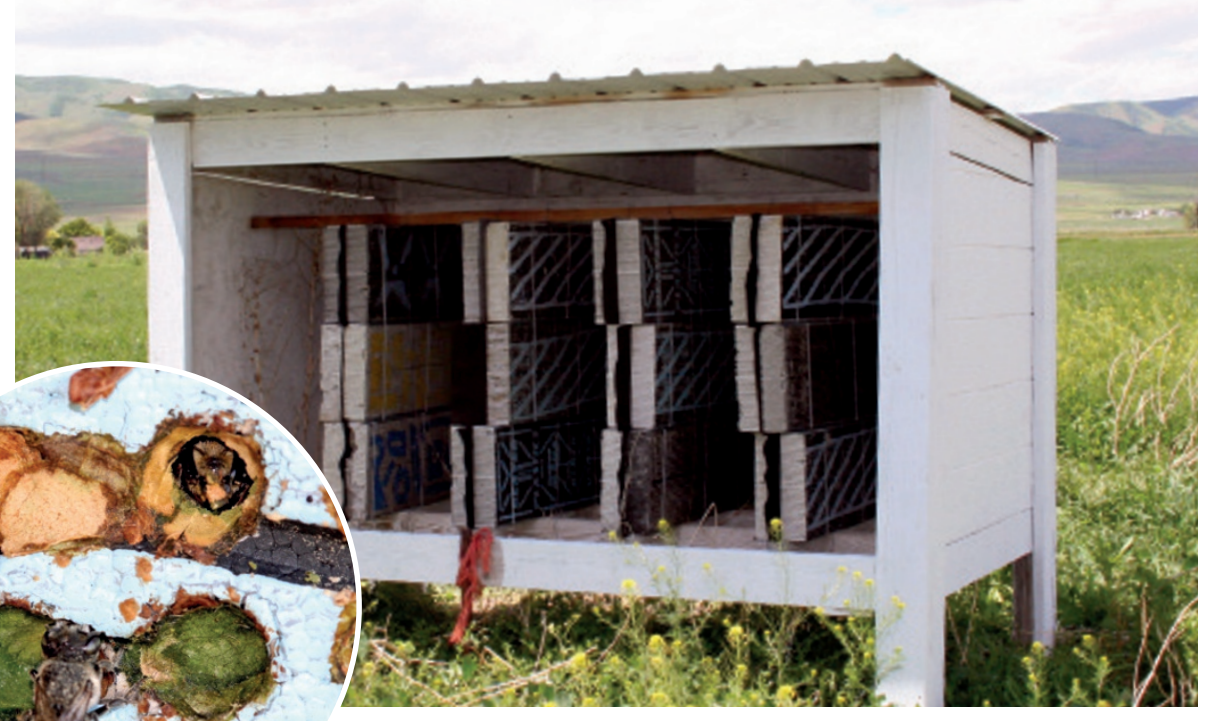

A purpose-built shelter with polystyrene nesting boards for the alfalfa leafcutter bee, Megachile rotundata (inset), in an alfalfa field in Utah.

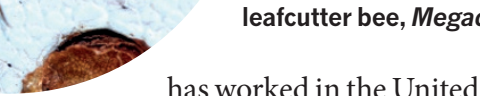

States to develop techniques for managing these and other species of wild bee. He says many research questions remain about which types of wild bees interact with which species of agricultural flowering plants — "And above all, why?" he asks.

Researchers are also looking at how to make portable nests that can guarantee sufficient pollination productivity to be worth nurturing wild bees and even transporting them from one pollination site to another. Researchers at the USDA's bee laboratory in Logan have tried varying the temperature during larval development to see what effect it has on the timing of the bees' emergence from their nests, and on their survival rates. And there is a small but growing number of private operations that offer solitary bees for sale. But these businesses are nothing like as reliable as honeybee production: the number of bees available from season to season is unpredictable and the pollination performance of any given batch depends heavily on environmental conditions and release techniques.

\section{KEEP IT WILD}

Although some species of solitary bees are suitable for management, researchers shy away from the word 'domestication'. Many wild bees have value in the untamed landscapes where they pollinate wild plants and help to anchor ecosystems in ways that provide indirect benefits, such as habitat for other insect species and suppression of pests.

Wild-bee populations are exposed to the same dangers as honeybee colonies, but with less protection. As industrial-scale farms plant larger and ever-more orderly swathes of the same few crops, it becomes harder for wild bees to find suitable flowers to forage in or to make nests in untilled ground or in, stray detritus. Monocropping is simplifying the diets of wild bees. If these bees had a more diverse, complex diet, asks Pitts-Singer, would that help to buffer them against pests and disease?

When researchers have a better understanding of how modern agriculture affects wild bees, they can start to explore improvements in landscapes and practices. The USDA has funded a four-year study to examine the best way to optimize farming landscapes to promote native and managed pollinators. The answers may be surprising: a 2015 study across 36 sites in the United Kingdom recorded a higher variety of bee species in urban areas than in farmland (K. C. R. Baldock et al. Proc. R. Soc. B 282, 20142849; 2015). Working out the optimum ecological balance for wild bees involves collecting them in the real world, as Romero is doing in Spain. It also requires expensive chemical analyses of wild bees' food sources, nests, pollen and bodies to follow the flow of food and agricultural chemicals through these increasingly artificial ecosystems. "To track it all the way through, it's just insanely hard and expensive," says PittsSinger: each sample can cost US\$150-200 to analyse with a mass spectrometer. And that is assuming you can even find the insects: "You have no idea what's happening in the wild lands," says Pitts-Singer. Wild-bee nests are hidden in the ground, tucked into tree stumps, burrowed into beetle tunnels, and inside snail shells.

Yet it is their wildness and diversity that makes solitary bees so valuable. They live alongside our existing agricultural systems, with different vulnerabilities and strengths from domesticated honeybees. And they promise to inject our agricultural landscape with a healthy dose of biodiversity and pollen.

Lucas Laursen is a freelance journalist based in Madrid. 